Check for updates

Cite this: RSC Adv., 2022, 12, 7612

Received 27th November 2021 Accepted 2nd February 2022

DOI: $10.1039 / \mathrm{d} 1 \mathrm{ra08673a}$

rsc.li/rsc-advances

\section{Conversion of plastic waste into fuel oil using zeolite catalysts in a bench-scale pyrolysis reactor $\uparrow$}

\author{
Krishnasamy Sivagami, ${ }^{\text {ad }}$ Keshav V. Kumar, ${ }^{\mathrm{c}}$ Perumal Tamizhdurai, (D)*b \\ Dhivakar Govindarajan, ${ }^{a}$ Madhiyazhagan Kumar $^{\mathrm{c}}$ and Indumathi Nambi ${ }^{\star a c}$
}

Catalytic pyrolysis of mixed plastic waste to fuel oil experiment was tested with ZSM- 5 zeolite (commercial and synthesized) catalysts along with other catalysts. The ZSM-5 zeolite catalyst was effectively produced using a hydrothermal technique via metakaolin as an alumina source. The catalytic pyrolysis of different types of plastic (single and multilayer) wastes in the presence of various catalysts was tested with a bench-scale pyrolysis setup with $2 \mathrm{~kg}$ per batch capacity. Polyolefin based plastics (low-density polyethylene, high-density polyethylene, and polypropylene), multilayer plastics such as biaxial oriented polypropylene (BOPP), metalized biaxial oriented polypropylene layers (MET BOPP), polyethylene terephthalate (PET), metalized polyethylene terephthalate (MET/PET), polyethylene terephthalate combined polyethylene (PET/PE), and mixed plastic waste collected from the corporation sorting center were pyrolyzed in a batch pyrolysis system with $1 \mathrm{~kg}$ feed to determine the oil, gas and char distributions. The performances of commercial ZSM-5 and lab synthesized ZSM-5 catalysts were compared for the pyrolysis of non-recyclable plastic wastes. Other commercial catalysts including mordenite and gamma alumina were also tested for pyrolysis experiments. The gross calorific value of oil obtained from different combinations of multilayer packaging waste varied between $10789-7156 \mathrm{kcal} \mathrm{kg}^{-1}$. BOPPbased plastic waste gave higher oil yield and calorific value than PET-based plastic waste. Sulfur content present in the oil from different plastic wastes was measured below the detection limit. The synthesized ZSM- 5 zeolite catalyst produced a maximum oil output of $70 \%$ and corresponding gas and char of $16 \%$ and $14 \%$ for LDPE plastic. The strong acidic properties and microporous crystalline structure of the synthesized ZSM-5 catalyst enables increased cracking and isomerization, leading to an increased breakup of larger molecules to smaller molecules forming more oil yield in the pyrolysis experiments. Residual char analysis showed the maximum percentage of carbon with heavy metal concentrations ( $\mathrm{mg}$ $\mathrm{kg}^{-1}$ ) in the range of viz., chromium (15.36-97.48), aluminium (1.03-2.54), cobalt (1.0-5.85), copper (115.37-213.59), lead (89.12-217.3), and nickel (21.05-175.41), respectively.

\section{Introduction}

The rate of generation of plastic waste is increasing exponentially. This is primarily because of the increased production of plastics and the low recycling rate around the globe. For instance, the production of plastics has increased from 250

${ }^{a}$ Environmental and Water Resources Division, Department of Civil Engineering, Indian Institute of Technology Madras, Chennai-600 036, India. E-mail: indunambi23@iitm.ac.in; Tel: +91-44-2257-4289

${ }^{b}$ Department of Chemistry, Dwaraka Doss Goverdhan Doss Vaishnav College (Autonomous), E.V.R. Periyar Road, Arumbakkam, Chennai, Tamil Nadu 600 106, India. E-mail: p.tamizhdurai@dgvaishnavcollege.edu.in; Tel: +91-9677146579

'Samudhyoga Waste Chakra Private Limited, IIT Madras Research Park, Tharamani, Chennai-600 113, India

${ }^{d}$ Industrial Ecology Group, School of Chemical Engineering, Vellore Institute of Technology, Vellore-632 014, Tamil Nadu, India

$\dagger$ Electronic supplementary information (ESI) available. See DOI: 10.1039/d1ra08673a million metric tons in 2008 to 335 million metric tons in $2016 .{ }^{1}$ However, only less than $10 \%$ of the total plastic waste generated is recycled, while the rest is found in landfills or oceans. ${ }^{2}$

The most commonly used areas of plastic in our daily lives are packaging, building and construction plastic, automotive, electrical and electronic, agriculture, and sports. ${ }^{3}$ The usage of plastic in these areas has been inevitable due to low price, the durability of plastic, prevention of food waste and contamination, and reduced weight of the packaging. On the downside, the non-degradable nature of plastic waste unbalances the ecosystem. About 5-13 million tons of plastic end up in the ocean every year. ${ }^{2}$ The municipal solid waste (MSW), which comprises $10-12 \%$ of plastic, is also burned, releasing toxic gases such as dioxins, furans, mercury, and polychlorinated biphenyls. ${ }^{4}$

Recycling plays a key role in ensuring these plastics do not reach the ocean or the landfill. Recycling is broadly classified into physical and chemical recycling. ${ }^{5}$ Physical recycling 
involves sorting, washing, cleaning, and shredding plastic waste to re-extrude plastic. The plastic waste undergoes oxidation, radiation, and heating in mechanical recycling, degrading the polymer quality. ${ }^{6}$ Additionally, it is challenging to treat mixed plastic waste through mechanical recycling due to the difference in melting point and processing temperature.

These disadvantages of mechanical recycling can be overcome with chemical recycling. Chemical recycling is a process of converting polymers to monomers through a thermochemical or catalytic process. Pyrolysis is a widely used chemical recycling process to convert different types of plastic waste to liquid fuel. Pyrolysis is a process of breaking down long-chain hydrocarbons into smaller chains with the application of heat and pressure in the absence of oxygen. The process is carried out in a wide range of temperatures from 300 to $900{ }^{\circ} \mathrm{C}$. The process yields three products (1) liquid oils, (2) noncondensable gases, and (3) char (solid). Studies have shown oil recovery of up to $80 \%$ with gaseous and char byproducts. ${ }^{7}$ The gaseous byproduct with a high calorific value is used as a secondary heat source to reduce the overall energy requirement of the system. ${ }^{8}$ The application of liquid oil includes usage in boilers for combustion, engines, turbines, and chemical feedstock. ${ }^{9}$

The conventional pyrolysis systems are temperaturedependent, and the liquid fuel recovered from the process might contain residues and impurities. ${ }^{\mathbf{1 0}}$ The low selectivity nature of the pyrolysis process often leads to uncontrolled product distribution. ${ }^{\mathbf{1 1}}$ Additionally, the conduct of polyolefinbased plastics such as high-density polyethylene (HDPE), lowdensity polyethylene (LDPE), and polypropylene (PP) is difficult in temperature-dependent processes in the absence of catalysts due to the crossed chain hydrocarbon structures. Thus, it is of critical importance to use a catalyst to generate products in the range of commercial-grade fuels such as gasoline to ensure economic viability for pyrolysis plants. ${ }^{\mathbf{1 2 - 1 5}}$

The usage of catalysts to improve product distribution and selectivity has been studied over the past two decades. A range of catalysts has been tested, such as commercial and domestic activated carbon, modified natural zeolite (NZ) catalyst, ${ }^{16}$ twostage catalysis using mesoporous MCM-41 followed by microporous ZSM-5, ${ }^{17} \mathrm{Ni} / \mathrm{Al}_{2} \mathrm{O}_{3}$ catalyst, ${ }^{18} \mathrm{HZSM}-5$ zeolite, $\mathrm{ZnO}$, silica, calcium carbide, alumina, magnesium oxide, zinc oxide and homogeneous mixture of silica and alumina, ${ }^{19}$ ZSM-5 zeolite and Red Mud. ${ }^{20}$ The usage of these catalysts improves the product distribution, reduces the temperature required for the process, and thus significantly reduces the energy consumption and ensures faster reaction time. ${ }^{21}$ Additionally, the high selectivity in catalytic pyrolysis holds a key advantage against the thermal degradation process by simulating isomerization. ${ }^{22}$

The catalytic processes can be broadly classified as homogeneous and heterogeneous processes. A homogenous catalyst is a single-phase catalyst, whereas a heterogeneous catalyst is a solid. Heterogeneous catalysts are widely used due to their ability to withstand extreme conditions such as temperatures up to $1300{ }^{\circ} \mathrm{C}$ and pressure of $35 \mathrm{MPa}$. Studies have shown acidbase catalysts (zeolite) to be more effective than less acidic catalysts (silica-alumina). ${ }^{23}$ Most of the above-mentioned studies have experimented with plastics such as LDPE, HDPE, and PP. However, as mentioned before, the real composition of plastic waste collected from municipal solid waste contains a lot of post-consumer packaging waste multi-layered plastic mixed with polyolefins. ${ }^{\mathbf{2 4 , 2 5}}$

Furthermore, from an operational point of view, given that the capacity of plastic pyrolysis plants ranges from 5 tons to 50 tons per day, the cost structure of the plant and its return of investment is highly dependent on the consumption, utility, and manpower expenses. ${ }^{26}$ The major cost of consumables includes the amount of catalyst used and the price per $\mathrm{kg}$ of the catalyst. ${ }^{27,28}$ Hence, the unit economics of the plant and its profitability is dependent on the catalyst expense, among other factors. Studies conclude that the type and amount of catalyst are the key distinctions between thermal and catalytic pyrolysis, and any system would aim to use catalysts at practically zero cost. ${ }^{29-31}$ Thus, it is of importance to study and compare different catalytic pyrolysis systems that are more efficient and cheaper than the commercially available catalysts. ${ }^{16,26}$ To date, very few studies have been published comparing the use of these catalysts for real plastic waste and its impact on product distribution. ${ }^{32-34}$ Besides, these studies have been carried out with real plastic waste with a catalyst such as red mud and zeolite. ${ }^{20}$

The study of real plastic waste includes the following (a) real plastic wastes from the residue of a material recovery facility (MRF) that respond differently to pyrolysis than simulated samples, which is composed of just a few pure plastics (b) a combination of multilayered plastic (MLPs) with polyolefinbased mixed plastic waste. A real plastic study with a low-cost catalyst would lead to a feasible solution to obtain a consistent pyrolysis oil quality and quantity. Based on the above discussion, it is well known that the study of mixed plastic waste with different catalysts is quite limited. Therefore, the interest of this study lies in the pyrolysis of actual plastic solid wastes collected in India exhaustively with the synthesized low-cost catalyst and commercial catalysts.

\section{Materials and methods}

3-[(Trimethoxysilyl)propyl] octadecyldimethylammoniumchloride (ODAC, 60\% methanol solution), metakaolin, and TEOS (tetraethyl orthosilicate) were purchased from Sigma Aldrich. Sodium hydroxide pellets $(\mathrm{NaOH})$ were purchased from S. D. Fine Chemicals Ltd. Tetrapropyl ammonium bromide (TPABr) was purchased from Merck, India.

\subsection{Preparation of metakaolin (metakaolinization)}

The metakaolin phase is amorphous and highly reactive as compared to the kaolin phase and that phase is obtained by dehydroxylation of kaolin at a higher temperature. In this study, we used metakaolin as an alumina source and treated it at $600{ }^{\circ} \mathrm{C}$ for $1 \mathrm{~h}$ with a heating rate of $10^{\circ} \mathrm{C} \min ^{-1}$ before using it. ${ }^{35}$

\subsection{Synthesis of micro-mesoporous zeolites ZSM-5 catalyst}

Micro-mesoporous ZSM-5 molecular sieves were synthesized hydrothermally from a reaction gel containing 3- 
[(trimethoxysilyl)propyl] octadecyldimethyl-ammoniumchloride (ODAC, 60\% methanol solution) and tetrapropyl ammonium bromide (TPABr) as templates by following a modified recipe of previously reported procedures. ${ }^{36}$ A typical synthesis gel was prepared as follows: solution A was prepared by adding $0.4 \mathrm{~g}$ of $\mathrm{NaOH}$ pellets, followed by the addition of $1.4 \mathrm{~g}$ of TPABr and $0.5 \mathrm{~g}$ of metakaolin in $67.5 \mathrm{~g}$ of distilled water under vigorous stirring at room temperature for $30 \mathrm{~min}$ until the solution was homogeneous. Finally, a gel was obtained by adding a homogenous mixture of $4.285 \mathrm{~g}$ of TEOS (tetraethyl orthosilicate) and $0.595 \mathrm{~g}$ of ODAC into solution A under vigorous stirring for $2 \mathrm{~h}$. Gels with chemical compositions containing different amounts of ODAC as represented by the formula, $1 \mathrm{Al}_{2} \mathrm{O}_{3}: 2.33 \mathrm{TPABr}: 2.22 \mathrm{Na}_{2}$ $\mathrm{O}: 11.04-11.85 \mathrm{SiO}_{2}: 0.26-1.6 \mathrm{ODAC}: 1666 \mathrm{H}_{2} \mathrm{O}$ were prepared to obtain the different ZSM-5 samples. The mixture was then transferred into a stainless-steel autoclave heated in an oven at $150{ }^{\circ} \mathrm{C}$ for $24 \mathrm{~h} .{ }^{37}$ The obtained crystallized product was washed, dried at $100{ }^{\circ} \mathrm{C}$ overnight, and calcined in air at $550{ }^{\circ} \mathrm{C}$ for $6 \mathrm{~h}$ with a heating rate of $1{ }^{\circ} \mathrm{C}$ per min. Other ZSM-5 samples were synthesized with different $\mathrm{SiO}_{2} / \mathrm{Al}_{2} \mathrm{O}_{3}$ ratios of $5,10,20$, and 50 by varying the TPABr/ODAC ratios. The synthesized catalyst is used for pyrolysis of plastic solid waste (PSW) and performance comparison with industrial catalysts. ${ }^{38}$

\subsection{Plastic waste sample collection}

Plastic waste samples were collected from different sources. Polyolefin wastes like polyethylene, polypropylene, and shredded mixed plastic waste were collected from plastic recyclers and corporation material recovery facilities in Chennai. Plastic wastes were collected from flexible packaging industries in Chennai.

\subsection{Batch plastic pyrolysis reactor}

Fig. 1 shows the photographic image of a plastic pyrolysis bench-scale plant. Batch pyrolysis experiments were carried out with $1 \mathrm{~kg}$ of PSW-based plastic waste and the required amount of catalysts like zeolite, ZSM-5 (commercial grade and synthesized), and mordenite. The PSW and the catalyst were fed into the inner chamber of the pyrolyzer through a feed inlet provision provided in the top lid of the pyrolyzer. The catalyst and feed plastics were added layer by layer and then mixed for the homogenous spread of the catalyst. The pyrolyzer unit was surrounded by a stainless steel outer chamber insulated with glass wool on the outside. The heating rate of the pyrolysis system was $10^{\circ} \mathrm{C} \mathrm{min}^{-1}$ till the set steady final temperature was reached. The temperature measurement was measured by a thermocouple, and the accuracy of the measurement was $\pm 3{ }^{\circ} \mathrm{C} .{ }^{39}$ The entire system was purged with nitrogen to maintain inert conditions. The catalytic pyrolysis experiments were carried out with different catalysts as shown in Table $1 .^{\mathbf{4 0 , 4 1}}$ Batch pyrolysis trials were conducted with different types of polyolefinic and multilayer packaging waste (LDPE, HDPE, PP, mixed plastic waste, and combination of MLPs) and catalysts (zeolite, ZSM-5, mordenite, and gamma aluminium). The feed to catalyst $(10: 1)$ ratio was used for all the experiments with a retention time of $90 \mathrm{~min}$ and a temperature range of 450$500{ }^{\circ} \mathrm{C} .{ }^{33,34}$ The resultant product yield (oil, char, and gas) in $w \mathrm{t} \%$ was quantified gravimetrically at the end of each experiment. The chemical characterization of the oil products was analyzed by GC-MS (Gas Chromatography-Mass Spectrometry).

\subsection{Chemical fingerprinting of pyrolysis oil}

Chemical fingerprinting of oil and char was done through GCMS (Agilent Technologies, USA). An HP-5 (30 m $\times 0.25 \mathrm{~mm})$ silica-based cross-linked column was used. The injector and detector temperatures were set at $300{ }^{\circ} \mathrm{C}$. The temperature was increased from $50{ }^{\circ} \mathrm{C}$ to $100{ }^{\circ} \mathrm{C}$ with a ramp rate of $10^{\circ} \mathrm{C} \mathrm{min}^{-1}$. The temperature was held at $100{ }^{\circ} \mathrm{C}$ for $120 \mathrm{~s}$ and was consequently increased to $250{ }^{\circ} \mathrm{C}$ by heating the system at a rate of $5{ }^{\circ} \mathrm{C} \mathrm{min}^{-1}$. After holding the temperature at $250{ }^{\circ} \mathrm{C}$ for $2 \mathrm{~min}$, the temperature was elevated to $300{ }^{\circ} \mathrm{C}$ with a ramp rate of

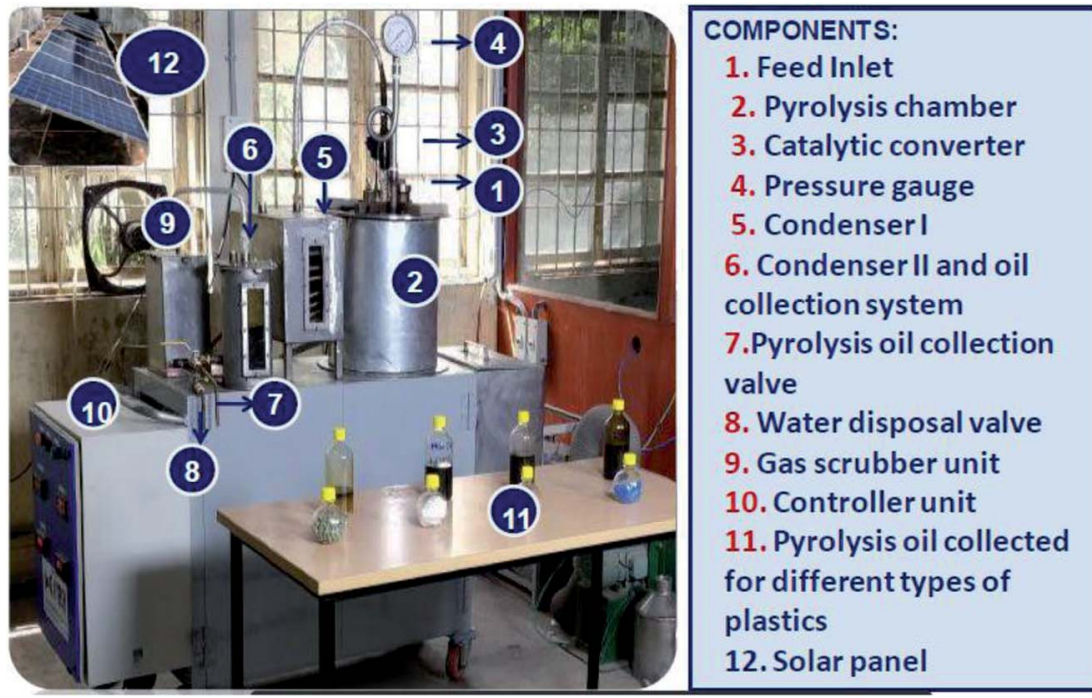

Fig. 1 Photograph of plastic pyrolysis bench-scale plant. 
Table 1 Types of plastic, feed ratio, and choice of catalyst in pyrolysis experiment

\begin{tabular}{|c|c|c|c|c|c|c|}
\hline S. no. & Type of plastic waste & $\begin{array}{l}\text { Plastic weight } \\
\text { (g) }\end{array}$ & Feed ratio & Catalyst & $\begin{array}{l}\text { Retention time } \\
(\mathrm{min})\end{array}$ & $\begin{array}{l}\text { Temperature } \\
\left({ }^{\circ} \mathrm{C}\right)\end{array}$ \\
\hline 1 & LDPE & 1000 & 100 & No catalyst & 90 & $450-500$ \\
\hline 2 & LDPE & 1000 & 100 & Zeolite & 90 & $450-500$ \\
\hline 3 & LDPE & 1000 & 100 & ZSM-5 (Com) & 90 & $450-500$ \\
\hline 4 & LDPE & 1000 & 100 & ZSM-5 (Syn) & 90 & $450-500$ \\
\hline 5 & LDPE & 1000 & 100 & Mordenite & 90 & $450-500$ \\
\hline 6 & LDPE & 1000 & 100 & Gamma alumina & 90 & $450-500$ \\
\hline 7 & HDPE & 1000 & 100 & Zeolite & 90 & $450-500$ \\
\hline 8 & $\mathrm{PP}$ & 1000 & 100 & Zeolite & 90 & $450-500$ \\
\hline 9 & Mixed plastic waste & 1000 & 100 & Zeolite & 90 & $450-500$ \\
\hline 10 & Metallized recycle plastic & 1000 & 100 & Zeolite & 90 & $450-500$ \\
\hline 11 & $\begin{array}{l}\mathrm{PET} / \mathrm{MET} / \mathrm{PET}+\text { polyolefinic mixed } \\
\text { plastic waste }\end{array}$ & 1000 & $50: 50$ & Zeolite & 90 & $450-500$ \\
\hline 12 & ВOPР/METBOPР & 1000 & $50: 50$ & Zeolite & 90 & $450-500$ \\
\hline 13 & BOPP/METBOPP + mixed plastic waste & 1000 & $40: 60$ & Zeolite & 90 & $450-500$ \\
\hline 14 & PET/FOIL/PET & 1000 & 100 & Zeolite & 90 & $450-500$ \\
\hline
\end{tabular}

$3{ }^{\circ} \mathrm{C} \mathrm{min}{ }^{-1}$ and was maintained at $300{ }^{\circ} \mathrm{C}$ for $15 \mathrm{~min} .{ }^{42}$ A sample volume of $1 \mu \mathrm{L}$ was injected in the splitless mode. Carrier gas (helium) was used at the rate of $1 \mathrm{~mL} \mathrm{~min}^{-1}$. MS was scanned from 35-550 amu at $1.562 \mathrm{u} \mathrm{s}^{-1}$. MS source and quadrupole temperatures were maintained at $150{ }^{\circ} \mathrm{C}$ and $230{ }^{\circ} \mathrm{C}$, respectively. Calibration curves were prepared through multiple dilution 20 element multi-elemental total petroleum hydrocarbons (TPH) standard (Supelco, USA). Agilent Technologies Mass Hunter software was used to determine the amount of TPH present in the fuel oil. NIST mass spectral database was used to compare the mass spectra of the unknown organic compounds in the solvent extract. ${ }^{32}$

\subsection{Reusability of catalyst}

The leftover catalyst from the experiments was collected and reused to evaluate its effectiveness. Different combinations of used and unused catalysts were tried to study the optimal reuse of the catalyst in the pyrolysis process. The results indicated a reduction in oil yield on reusing the catalyst. The lower operating temperature of $450{ }^{\circ} \mathrm{C}$ decreased the stability and selectivity of the catalyst affecting oil yield as zeolite requires a higher reaction temperature.

\subsection{Analysis of pyrolysis oil, gas, and char}

The physicochemical characteristics of oil and char recovered from the polyolefinic and multilayer packaging-based waste were analyzed using ASTM methods. The properties of oil like gross calorific value, total sulfur content, kinematic viscosity, density, cetane index, carbon level, and flash point of fuel oil recovered from the plastic waste were characterized using ASTM methods (ASTM D4868-2017, ASTM D4868-2017, ASTM D42942016e1, ASTM D445-2017, ASTM D4052-2018, ASTM D9762016, ASTM D92-2016B). The gross calorific value of the pyrolysis char was determined through a bomb calorimeter (ASTM D 5865:13). The concentration of heavy metals and sulfur present in the char were determined using ASTM D 6357:2011, ASTM
E775 methods. The percentage of polycyclic aromatic hydrocarbons present in the char was determined through GC-MS. ${ }^{16,43}$

\section{Results and discussion}

\subsection{Structural, textural, morphological, and acidic properties of ZSM-5 zeolite}

X-ray diffraction (XRD) was carried out at a wavelength of 1.542 $\AA$ ( $\mathrm{Cu} \mathrm{K} \alpha$ radiation) and was used to identify the crystalline phases present in the ZSM-5 zeolite catalyst. Fig. 2a shows the large-angle powder XRD patterns of the synthesized ZSM-5 zeolite prepared by the hydrothermal method. The observed characteristic diffraction peaks at $\theta=7.98^{\circ}, 8.82^{\circ}, 14.82^{\circ}$, $23.14^{\circ}, 23.96^{\circ}$, and $24.44^{\circ}$ are associated with [011], [020], [031], [051], [303], and [313] planes with the $d$-spacing values of 1.11, $1.00,0.59,0.39,0.37$, and $0.36 \mathrm{~nm}$, respectively. These values were completely intrinsic to the ZSM-5 zeolite catalyst structure and correspond to the JCPDS card no: 42-0024. The XRD results indicate that no diffraction peaks of the impurity phase were found, and the specific MFI structure was maintained on all the samples. The sharp peaks indicate that the synthesized ZSM-5 zeolite samples possess good crystallinity. The XRD result is similar to the one reported in the literature. ${ }^{44}$ The average crystallite size of the as-synthesized ZSM-5 zeolites is $30 \mathrm{~nm}$ and was calculated using the Debye-Scherrer formula $L=0.89 \lambda /$ $(\beta \cos \theta)$, where $L$ is the average crystallite size, $\lambda$ is the $\mathrm{X}$-ray wavelength $(0.154 \mathrm{~nm}), \theta$ is the Bragg diffraction angle, and $\beta$ is the full width at half maximum (FWHM) of the observed peak. The peak position and FWHM were obtained by fitting the peaks with two Gaussian curves in order to find the true peak position and width corresponding to the monochromatic $\mathrm{CuK} \alpha$ radiation.

The nitrogen adsorption and desorption isotherms of the synthesized ZSM-5 zeolites are shown in Fig. 2b. The sample shows a type IV isotherm. The ZSM-5 sample exhibits a broader hysteresis loop from $P / P_{0}=0.45$ to $P / P_{0}=1$, which is due to the formation of additional mesopores. The experimentally determined surface area and pore volumes of synthesized ZSM-5 are 

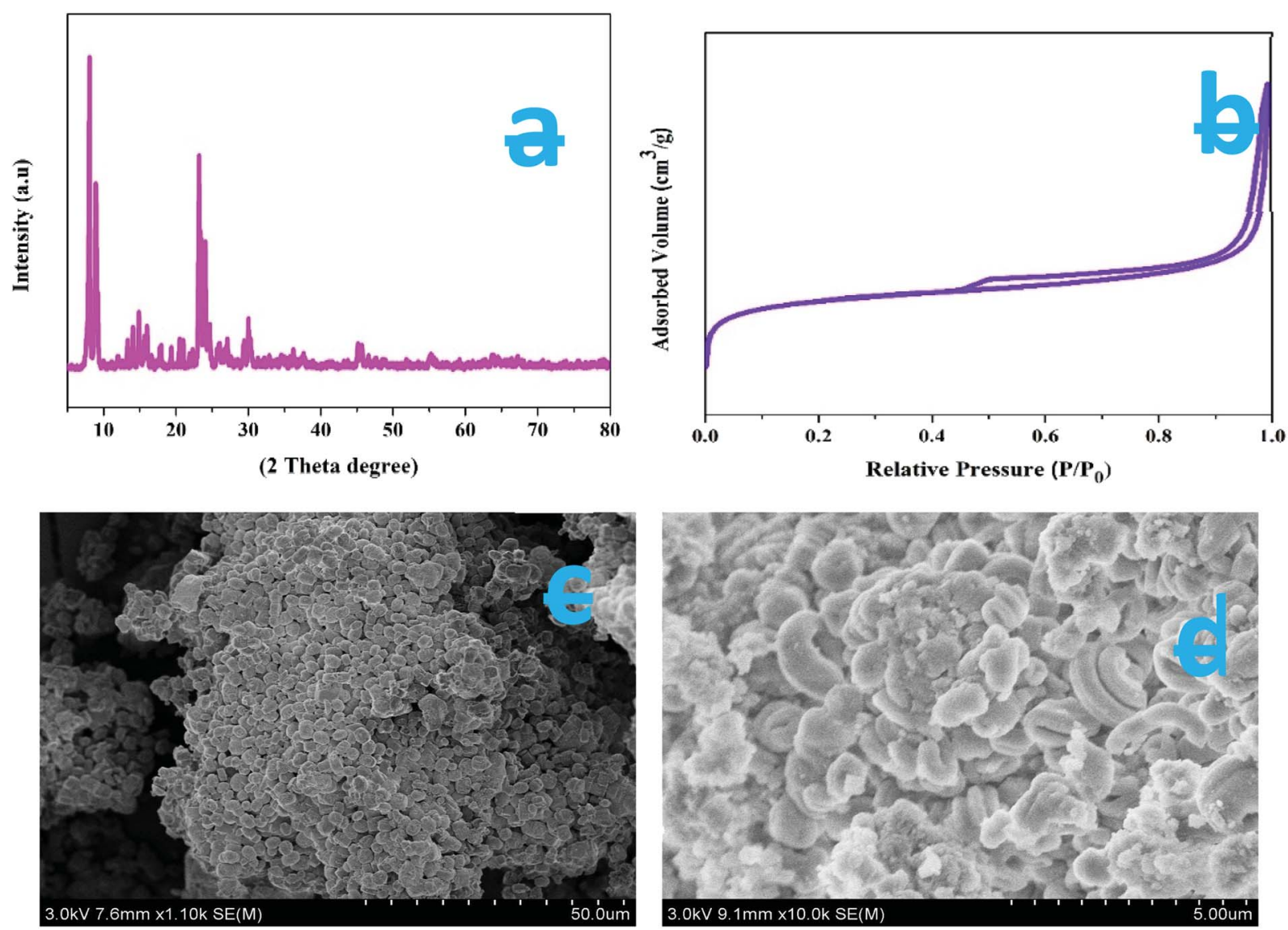

Fig. 2 (a) XRD patterns of as-synthesized samples, (b) $\mathrm{N}_{2}$ adsorption/desorption isotherms of as-synthesized ZSM-5 zeolite, (c \& d) HR-SEM images of synthesized ZSM- 5 catalyst.

$326.6 \mathrm{~m}^{2} \mathrm{~g}^{-1}$ and $0.38 \mathrm{~cm}^{3} \mathrm{~g}^{-1}$ (micropore volume, $0.08 \mathrm{~cm}^{3}$ $\left.\mathrm{g}^{-1}\right)$, respectively. The micropore volumes of the three samples are nearly the same. These results indicate that the additional mesoporosity was generated alongside the microporosity.

Fig. $2 \mathrm{c}$ and $\mathrm{d}$ are the HR-SEM images of synthesized ZSM-5, zeolites, respectively. The SEM images clearly suggest that all the samples obtained show a similar hexagonal cubic-like morphology and relatively have similar hexagonal cubic micro-blocks of about 320-360 nm in length without agglomeration. Furthermore, it is noted that the individual hexagonal cubic micro-blocks are made up of closely packed nanocrystals. The surface of ZSM-5 zeolite micro-blocks was slightly rougher. The rough surface is likely due to the hexagonal cubic microblocks that are constructed by the numerous small nanosized primary ZSM-5 particles, whose sizes vary from 26 to $35 \mathrm{~nm}$, as implied by the XRD results. Also, from Fig. $2 \mathrm{c}$ and d, it is noticed that the nanosized primary ZSM-5 particles are aggregated with voids. A slight variation is noticed in the particle sizes measured by XRD and SEM. The small difference arises since SEM measurements are based on the difference between the visible grain boundaries, whereas XRD calculations measure the extended crystalline region that diffracts X-rays coherently. Hence, the XRD technique is relatively straightforward and accurate.
The acidic properties of the synthesized ZSM-5 zeolite catalysts were evaluated by the $\mathrm{NH}_{3}$-TPD technique. The corresponding TPD profiles of the ZSM-5 zeolites displayed in Fig. 3 show that ZSM-5 zeolite has two desorption peaks observed at around $200{ }^{\circ} \mathrm{C}$ (low-temperature peak) and $500{ }^{\circ} \mathrm{C}$ (hightemperature peak). The low-temperature peak is attributed to the ammonia desorption from weak acid sites, though the hightemperature peak is attributed to the ammonia desorption from strong acid sites (Brønsted and Lewis acid sites). The weak acid strength of ZSM-5 zeolite is due to the presence of amorphous aluminosilicates of the macropore walls.

\subsection{Batch pyrolysis experiment with polyolefin and PSW plastic waste}

3.2.1 Comparison of thermal and catalytic pyrolysis. Pyrolysis temperature range of 450 to $500{ }^{\circ} \mathrm{C}$ was applied during the thermocatalytic depolymerization of different varieties of plastics. Zeolite beads were used as the catalyst material for the two-stage catalytic cracking of polymers. Zeolite was added into the pyrolyzer reactor along with the plastics for the in situ cracking process and the ratio of plastic and zeolite was fixed as $10: 1$, which was chosen based on previous studies. Petroleum hydrocarbons produced during pyrolysis were cracked in an $e x$ situ manner. Pyrolysis product yield (oil, char, and gas) was 


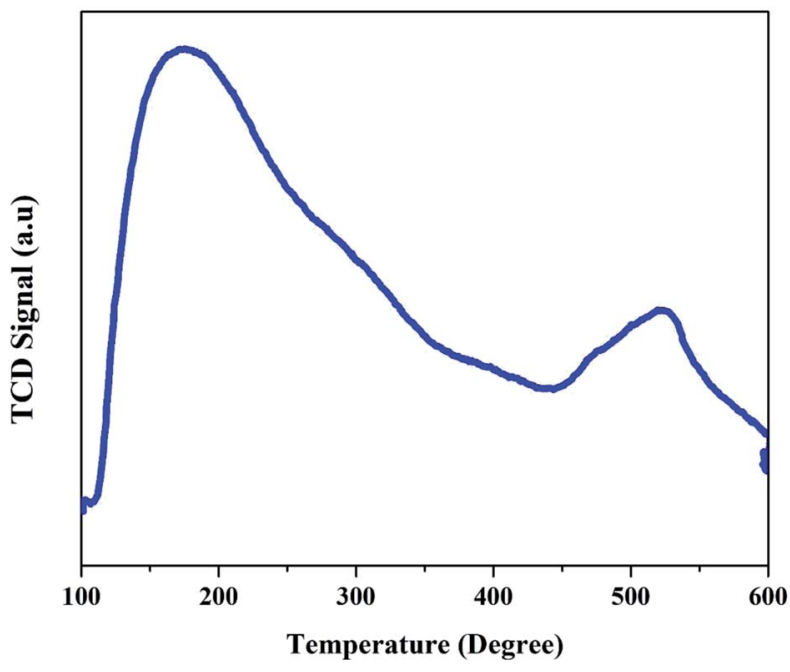

Fig. $3 \mathrm{NH}_{3}$-TPD profiles of as-synthesized ZSM-5 zeolite.

estimated based on the weight obtained for the char and oil at the end of the pyrolysis process, and the pyrolysis product yields obtained at different conditions are given in Table 2 . In the case of thermal pyrolysis (without catalyst), $37 \mathrm{wt} \%$ and $15 \mathrm{wt} \%$ of oil and char yields were obtained, respectively. In the case of catalytic pyrolysis, a maximum yield of $70 \mathrm{wt} \%$ of oil was observed for the same temperature range. The yield of char significantly reduced from $15 \%$ to $8 \%$ in the presence of the catalyst, similar to the drop in the yield of gaseous compounds $(8 \%)$. The strong acidic properties and microporous crystalline structure of the catalyst enable increased cracking and isomerization, leading to an increased breakup of the larger molecules to smaller molecules forming gaseous and liquid yields. However, compared to other studies where the yield of gaseous compounds has increased in the presence of the catalyst, the present study observes an increase in the yield of oil. The increase in oil yield over the gaseous output compared to other studies could be influenced by several factors such as the size of the catalyst and the nature of contact between the catalyst and the feedstock, indicating the effect of conditions on the yield of both thermal and catalytic pyrolysis.

3.2.2 Pyrolysis product yield. Pyrolysis of commercial LDPE plastic bags resulted in pyrolysis oil yield of $44-49 \mathrm{wt} \%$, a gas yield of 41-50 wt\%, and char yield of 5-9 wt\% for in situ and/or ex situ catalytic pyrolysis process. Among which the zeolite catalyst provided in both in situ and ex situ arrangement resulted in the highest gas yield of $50 \mathrm{wt} \%$ and lowest solid yield of $8 \mathrm{wt} \%$ with the oil yield of $42 \mathrm{wt} \%$. Various studies have also reported the increased production of gas with the utilization of zeolite on polyethylene compared to the gas yield of catalytic pyrolysis on other plastic feedstocks (using ZSM), reflecting the high acidic nature of catalyst incentivizing cracking of large molecules. ${ }^{7,45}$

Pyrolysis of waste plastics obtained from the municipality of Chennai resulted in generating $48-58 \mathrm{wt} \%$ of oil and $27-35 \mathrm{wt} \%$ of char. Similar to commercial plastic LDPE bags, municipal mixed plastics resulted in high gas yields for the zeolite provided in both in situ and ex situ ways. The addition of graphite to the mixture in the ex situ zeolite catalyst experiment resulted in the highest oil yield of $58.65 \mathrm{wt} \%$, a gas yield of $14.35 \mathrm{wt} \%$, and a char yield of $27 \mathrm{wt} \%$. The increase in the yield of oil due to the addition of graphite could be attributed to the surface area and functional groups present in the graphite leading to enhanced cracking of the compounds.

Pyrolysis of HDPE waste produced char of $37 \mathrm{wt} \%$ and oil of $52 \mathrm{wt} \%$. The reason for higher char yield was mainly due to higher inorganic content present in the plastics and unconverted plastics due to incomplete pyrolysis. ${ }^{46}$ Apparently, laminated metalized plastic resulted in the higher char production of $70 \mathrm{wt} \%$ and the least oil yield of $13 \mathrm{wt} \%$ due to higher aluminum and zinc metal concentrations and filler material present in the plastics. Commercial polypropylene plastic resulted in the production of $32 \mathrm{wt} \%$ oil, $31 \mathrm{wt} \%$ gas, and $37 \mathrm{wt} \%$ char.

Table 2 Pyrolysis product yield (oil, char, and gas) at the end of the pyrolysis process

\begin{tabular}{|c|c|c|c|c|c|c|}
\hline \multirow[b]{2}{*}{ S. no. } & \multirow[b]{2}{*}{ Input quality } & \multirow[b]{2}{*}{ Catalyst } & \multirow[b]{2}{*}{ Temp set point $\left({ }^{\circ} \mathrm{C}\right)$} & \multicolumn{3}{|c|}{ Product output (wt\%) } \\
\hline & & & & Oil & Gas & Char \\
\hline 1 & LDPE & Without catalyst & $450-500$ & 37 & 48 & 15 \\
\hline 2 & LDPE & Zeolite & $450-500$ & 50 & 42 & 8 \\
\hline 3 & LDPE & ZSM-5 (Syn) & $450-500$ & 70 & 16 & 14 \\
\hline 4 & LDPE & ZSM-5(Com) & $450-500$ & 46 & 12 & 42 \\
\hline 5 & LDPE & Mordenite & $450-500$ & 44 & 36 & 20 \\
\hline 6 & LDPE & Gamma alumina & $450-500$ & 40 & 32 & 28 \\
\hline 7 & HDPE & Zeolite & $450-500$ & 52 & 11 & 37 \\
\hline 8 & $\mathrm{PP}$ & Zeolite & $450-500$ & 32 & 31 & 37 \\
\hline 9 & Mixed plastic waste & Zeolite & $450-500$ & 53 & 35 & 12 \\
\hline 10 & Metallized recycle plastic & Zeolite & $450-500$ & 13 & 17 & 70 \\
\hline 11 & $\begin{array}{l}\mathrm{PET} / \mathrm{MET} / \mathrm{PET}+\text { polyolefinic mixed } \\
\text { plastic waste }\end{array}$ & Zeolite & $450-500$ & 30 & 35 & 35 \\
\hline 12 & ВОРР/МЕТВОРР & Zeolite & $450-500$ & 60 & 25 & 15 \\
\hline 13 & BOPP/METBOPP + mixed plastic waste & Zeolite & $450-500$ & 35 & 30 & 35 \\
\hline 14 & $\mathrm{PET} / \mathrm{FOIL} / \mathrm{PET}$ & Zeolite & $450-500$ & 10 & 42 & 48 \\
\hline
\end{tabular}


Different types of plastic wastes like biaxial oriented polypropylene (BOPP), metalized biaxial oriented polypropylene layers (MET BOPP), polyethylene terephthalate (PET), metalized polyethylene terephthalate (MET/PET), polyethylene terephthalate combined polyethylene (PET/PE), and mixed plastic wastes were pyrolyzed in a batch pyrolysis system of $1 \mathrm{~kg}$ to determine the oil, gas, and char distributions. Various catalysts like zeolite, mordenite, ZSM-5, HZSM-5, and MCM-41 were extensively studied by researchers for polyolefin-based plastic wastes. ${ }^{17,47}$ BOPP/MET BOPP type plastic waste yielded $65-70 \%$ oil. BOPP/MET BOPP (40\%) in combination with mixed plastic waste $(60 \%)$ gave around $35-40 \%$ oil yield. PET/poly and mixed plastic waste yielded around $30-40 \%$ oil due to the presence of $\mathrm{PE}$ and PP present in the mixed plastic waste. PET/MET PET/ POLY (50\%) and mixed plastic waste (50\%) yielded around $25-30 \%$ oil due to the presence of PE and PP present in the mixed plastic waste. The gas and char composition account for 70-75\% of PET and MET/PET-based plastic waste. The presence of aluminium foil and PET in the plastic waste (PET/FOIL/PET) gives only $10-15 \%$ oil with more char. The details of plastic feed, catalyst, the temperature used, and product output obtained (wt\%) in the pyrolysis experiments are listed in Table 2. The TPH composition (C1-C10, C11-C20, and C21-C30) of diesel was compared with TPH composition of pyrolysis oil obtained with catalysts (ZSM-5, mordenite, and $\gamma$-alumina) and displayed in Fig. 4. The TPH composition of pyrolysis obtained with ZSM-5 catalyst showed an almost similar composition to diesel. $^{48}$

\subsection{Plastic pyrolysis oil and char characterization}

3.3.1. Analysis of pyrolysis oil. In this study, we tried to evaluate the performance of zeolite with different layers of polyolefin waste and PSW combinations present in flexible packaging and municipal solid waste. The major steps involved in the catalytic reactions during pyrolysis are cracking, oligomerization, cyclic aromatic compound formation, and isomerization reactions. ${ }^{47}$ The secondary reactions are mainly based on cracking, rupture of rings, and aromatization, which lead to

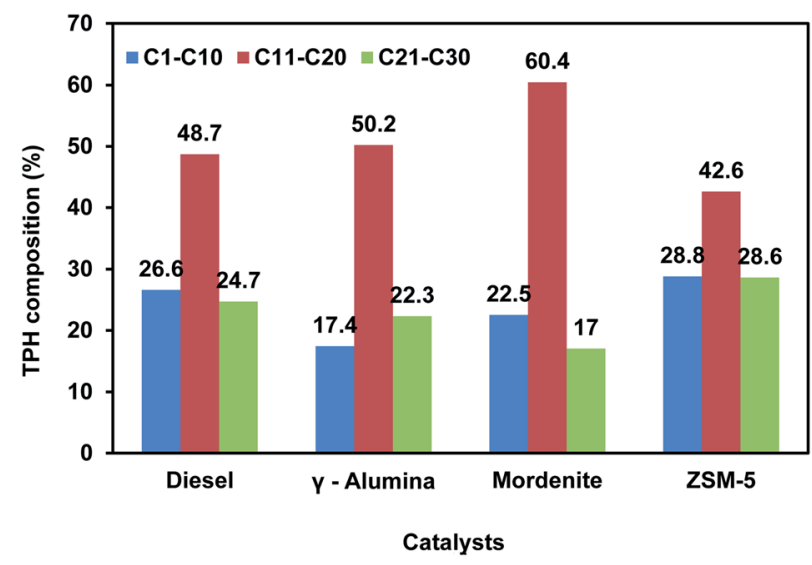

Fig. 4 TPH distribution in LDPE pyrolysis oil with different catalysts. the formation of hydrocarbons in the range of (nC4 to nC10) and low molecular weight aromatics. ${ }^{49}$ The formation mechanism of linear alkenes can be generally attributed to mid-chain b-scission reactions of midchain secondary alkyl radicals. Analysis of pyrolysis oil through GC-MS shows significant production of a large fraction of unsaturated hydrocarbons that include linear alkanes and alkenes (dienes, trienes) in the pyrolysis oil.50 The GC-MS chromatogram of pyrolysis oil is shown in ESI Fig. S1.†

The physicochemical and thermal characteristics of pyrolysis oil obtained from LDPE compared with commercial diesel and fuel oil are given in Table 3. Calorific value is one of the important characteristics based on which the quality of the fuel is evaluated for further applications. The calorific value for various plastics with zeolite catalysts is displayed in Fig. 5 . The calorific values of commercial-grade LDPE were within the range of 40 to $42 \mathrm{~kJ} \mathrm{~g}^{-1}$. The calorific values for mixed waste plastics obtained from the municipal corporation were found to be 38 to $39 \mathrm{~kJ} \mathrm{~g}^{-1}$. The calorific values of HDPE waste plastic and laminated metalized plastic-based pyrolysis oils were observed to be 41 and $37 \mathrm{~kJ} \mathrm{~g}^{-1}$, respectively. The gross calorific value of the pyrolysis oil obtained from different combinations of PSW varied between $45-30 \mathrm{~kJ} \mathrm{~g}^{-1}$. BOPP-based plastic waste gave higher oil yield and calorific value compared to PET-based PSWs. The calorific value of mixed waste plastics obtained from the municipal corporation with PSWs like BOPP and PET was found to be around 45 and 30 $\mathrm{kJ} \mathrm{g}^{-1}$. The calorific values of BOPP and laminated metalized plastic-based pyrolysis oil were observed to be 45 and $30 \mathrm{~kJ} \mathrm{~g}^{-1}$, respectively. These values are found to be similar to those reported for waste plastic pyrolysis oil in other studies, which are in the range of $30-47 \mathrm{~kJ} \mathrm{~g}^{-1}$ depending on the input plastic quality. ${ }^{51,52}$ The lowest calorific value of $30 \mathrm{~kJ} \mathrm{~g}^{-1}$ obtained from PET samples can be due to terephthalate formation during the thermal degradation process. Based on the results, it is evident that the pyrolysis oil obtained from the processing of PSWs with mixed plastic waste will be a feasible option for further applications that require a certain calorific value of the oil.

3.3.2. Effect of plastic-type on carbon number distribution in the pyrolysis oil. The hydrocarbon range present in different plastic pyrolysis oils was compared with diesel to evaluate the combustion performance. The C5-C10, C11-C20, and C21-C30 carbon numbers present in BOPP, METBOPP, PET/FOIL/PET, PET/MET PET/PE, and BOPP/MET PET samples were analyzed from GC-MS chromatogram. The percentage area of (C5-C10) compounds varies in the range of 8.9-23.6 (\%). The mediumrange hydrocarbons (C11-C20) vary from 27.5-60.5(\%). The heavier fractions (C21-C30) vary in the range of 24.7-55.7 (\%). Pyrolysis oil obtained from polyethylene have a higher calorific value due to the presence of paraffinic, olefinic, and aromatic hydrocarbons [C12, C14, C21]. Long-chain hydrocarbons generally have low combustion temperatures.

3.3.3. Pyrolysis char characterization. The pyrolysis char obtained from different batch experiments varied in the range of 8-70 (\%) depending upon the type of plastic used. Char yield from polyolefin-based plastics LDPE, PP, and BOPP varied in the range of 8-20 (\%). The additives added in the HDPE-based waste increased the char quantity to $30(\%)$. PSW based waste 
Table 3 Properties of the pyrolysis oil from different types of plastics

\begin{tabular}{|c|c|c|c|c|c|c|}
\hline S. no. & Pyrolysis oil & $\begin{array}{l}\text { Kinematic viscosity } \\
\text { at } 40^{\circ} \mathrm{C}(\mathrm{cSt})\end{array}$ & $\begin{array}{l}\text { Gross calorific } \\
\text { value }\left(\mathrm{kJ} \mathrm{g}^{-1}\right)\end{array}$ & $\begin{array}{l}\text { Sulfur content } \\
(\mathrm{wt} \%)\end{array}$ & $\begin{array}{l}\text { Density at } 15^{\circ} \mathrm{C} \\
\mathrm{kg} \mathrm{m}^{-3}\end{array}$ & $\begin{array}{l}\text { Flash point } \\
\left({ }^{\circ} \mathrm{C}\right)\end{array}$ \\
\hline 1 & LDPE with ZSM-5 & 11.7 & 41 & $<0.1$ & 780 & 31 \\
\hline 2 & LDPE without catalyst & 1.08 & 40 & $\sim 0.0017$ & 811.9 & 79 \\
\hline 3 & LDPE with zeolite & 2.49 & 42 & $\sim 0.009$ & 814.7 & 52 \\
\hline 4 & Commercial diesel & $1-4.11$ & 45 & $<0.1-0.6$ & 799 & $52-96$ \\
\hline 5 & Commercial foil-2 & $2-3.6$ & $40-45$ & $0.1-0.6$ & $900-1010$ & $40-75$ \\
\hline
\end{tabular}

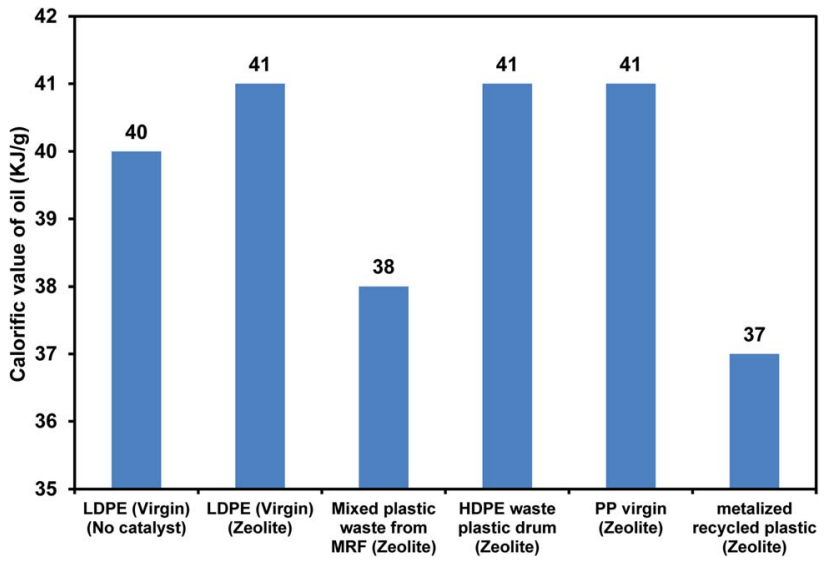

Fig. 5 Variation in TPH distribution for waste plastic with different compositions

yielded 15-48 (\%) char. PET/FOIL/PET combination and laminated metalized recycled plastic gave a maximum amount of char in the range of 50-70 (\%). The char obtained from plastic pyrolysis using different plastic wastes like LDPE, biaxial oriented polypropylene (BOPP), and PET/PET-based char were characterized for the presence of heavy metals, and concentrations $\left(\mathrm{mg} \mathrm{kg}^{-1}\right)$ in the range of viz., chromium (15.36-97.48), aluminium (1.03-2.54), cobalt (1.0-5.85), copper (115.37213.59), lead (89.12-217.3), and nickel (21.05-175.41), respectively, were found. Sulfur as $\left(\mathrm{SO}_{3}\right)$ concentrations in the char varied from $34-441 \mathrm{mg} \mathrm{kg}^{-1}$. The composition of aliphatic, aromatic, and polar fractions of char was analyzed through GCMS. The peaks were identified by comparing them with the NIST library. The compounds having a carbon number ranging from nC13 to nC33 showed an aliphatic fraction. The retention time of the aliphatic fraction showed a hump representing the unresolved hydrocarbon fraction. ${ }^{53}$

\section{Conclusion}

The study aimed to develop a low-cost catalyst and conduct experiments with a larger quantity of feed to obtain products such as oil, char, and non-condensable gas. A ZSM-5 zeolite catalyst was synthesized by hydrothermal method using metakaolin as an alumina source. The XRD analysis confirmed the formation of ZSM-5 phases with a high surface area of $326.6 \mathrm{~m}^{2}$ $\mathrm{g}^{-1}$ (BET analysis) and hexagonal cubic-like morphology (SEM analysis). From TPD analysis, it was confirmed that the synthesized catalysts possess both Brønsted and Lewis acid sites. Catalytic pyrolysis of mixed plastic waste to fuel oil experiment was tested with ZSM-5 zeolite (commercial and synthesized) catalysts along with other catalysts. In the case of thermal pyrolysis (without catalyst), $37 \mathrm{wt} \%$ and $15 \mathrm{wt} \%$ of oil and char yields were obtained, respectively. Among the tested catalysts, the synthesized ZSM-5 zeolite produced high oil content $(70 \mathrm{wt} \%)$ with low char products $(14 \mathrm{wt} \%)$ compared to other catalysts using LDPE as feed. Compared to polyolefinbased waste plastics, pyrolysis oil derived from PET-based MLPs and laminated metalized recycled plastics with mixed plastic yields less oil. The produced oil and char were characterized using GC-MS to determine the carbon range fraction in the oil, and other instruments were used to measure the physico-chemical properties of these products. The pyrolysis oil produced from LDPE by ZSM-5 catalyst possessed a gross calorific value of $41 \mathrm{~kJ} \mathrm{~g}^{-1}$, almost equal to commercial diesel and fuel oil.

\section{Conflicts of interest}

There are no conflicts to declare.

\section{Acknowledgements}

The authors gratefully acknowledge the financial support of the Department of Science \& Technology (DST) for the WOS-A fellowship for Sivagami. K [Sanction order no. SR/WOS-A/ET1064/2015], UAY project sponsored by the Ministry of Human Resources Development and Bharat Petroleum Corporation Ltd., and Government of India in carrying out this research work. The authors also acknowledge Dr Divya Priya. G for her inputs in improvement.

\section{References}

1 Statista, Production of plastics worldwide from 1950 to 2018 (in million metric tons), Statista website, 2022, https:// www.statista.com/statistics/282732/global-production-ofplastics-since-1950/, accessed 02 Feb 2022.

2 S. Kumar, R. Prakash, S. Murugan and R. K. Singh, Energy Convers. Manage., 2013, 74, 323-331.

3 W. Leal Filho, U. Saari, M. Fedoruk, A. Iital, H. Moora, M. Klöga and V. Voronova, J. Cleaner Prod., 2019, 214, 550558. 
4 V. L. Mangesh, S. Padmanabhan, P. Tamizhdurai, S. Narayanan and A. Ramesh, J. Hazard. Mater., 2020, 386, 121453.

5 G. Hu, J. Li and G. Zeng, J. Hazard. Mater., 2013, 261, 470490.

6 E. A. H. Zubaidy and D. M. Abouelnasr, Process Saf. Environ. Prot., 2010, 88, 318-326.

7 R. Miandad, M. A. Barakat, A. S. Aburiazaiza, M. Rehan and A. S. Nizami, Process Saf. Environ. Prot., 2016, 102, 822-838.

8 K. Rajendran, R. Lin, D. M. Wall and J. D. Murphy, Sustainable Resource Recovery and Zero Waste Approaches, 2019, pp. 65-78.

9 M. Balat, M. Balat, E. Kirtay and H. Balat, Energy Convers. Manage., 2009, 50, 3147-3157.

10 N. Borsodi, N. Miskolczi, A. Angyal, L. Bartha, J. Kohán and A. Lengyel, 45th International Petroleum Conference, June 13, 2011, Bratislava, Slovak Republic. Catalyst, 2011.

11 P. Lettieri and S. M. Al-Salem, Waste, 2011, 233-242.

12 P. P. Falciglia and F. G. A. Vagliasindi, Environ. Technol., 2014, 35, 2280-2288.

13 Y. Zhang, Y. Cui, S. Liu, L. Fan, N. Zhou, P. Peng, Y. Wang, F. Guo, M. Min, Y. Cheng, Y. Liu, H. Lei, P. Chen, B. Li and R. Ruan, Bioresour. Technol., 2020, 297, 122480.

14 Y. Zhang, S. Liu, L. Fan, N. Zhou, M. Mubashar Omar, P. Peng, E. Anderson, M. Addy, Y. Cheng, Y. Liu, B. Li, J. Snyder, P. Chen and R. Ruan, Energy Convers. Manage., 2018, 159, 76-84.

15 Y. Zhang, P. Chen, S. Liu, P. Peng, M. Min, Y. Cheng, E. Anderson, N. Zhou, L. Fan, C. Liu, G. Chen, Y. Liu, H. Lei, B. Li and R. Ruan, Bioresour. Technol., 2017, 230, 143-151.

16 Y.-R. Chen, Environ. Technol., 2016, 37, 3139-3145.

17 D. K. Ratnasari, M. A. Nahil and P. T. Williams, J. Anal. Appl. Pyrolysis, 2017, 124, 631-637.

18 I. Aminu, M. A. Nahil and P. T. Williams, Energy Fuels, 2020, 34(9), 11679-11689.

19 J. Shah, M. Rasul Jan, F. Mabood and F. Jabeen, Energy Convers. Manage., 2010, 51(12), 2791-2801.

20 A. López, I. de Marco, B. M. Caballero and M. F. Laresgoiti, Appl. Catal., B, 2011, 104(3-4), 211-219.

21 N. Xu, W. Wang, P. Han and X. Lu, J. Hazard. Mater., 2009, 171, 914-917.

22 M. Kriipsalu, M. Marques and A. Maastik, J. Mater. Cycles Waste Manage., 2008, 10, 79-86.

23 H. Schmidt and W. Kaminsky, Chemosphere, 2001, 45, 285290.

24 T. Karayildirim, J. Yanik, M. Yuksel and H. Bockhorn, Fuel, 2006, 85, 1498-1508.

25 Z. Wang, Q. Guo, X. Liu and C. Cao, Energy Fuels, 2007, 21, 957-962.

26 W. Wan Mahari, N. Zainuddin, W. Wan Nik, C. Chong and S. Lam, Energies, 2016, 9, 780.
27 J.-L. Shie, C.-Y. Chang, J.-P. Lin, D.-J. Lee and C.-H. Wu, Energy Fuels, 2002, 16, 102-108.

28 J.-L. Shie, J.-P. Lin, C.-Y. Chang, D.-J. Lee and C.-H. Wu, Resour., Conserv. Recycl., 2003, 39, 51-64.

29 S. Akbari, A. Nour, S. Jamari and A. Rajabi, Aust. J. Basic Appl. Sci., 2016, 10, 66-74.

30 C.-C. Chan and Y.-C. Chen, Sep. Sci. Technol., 2002, 37, 34073420 .

31 L.-X. Xia, S.-W. Lu and G.-Y. Cao, Chem. Eng. Commun., 2004, 191, 1053-1063.

32 S. Cheng, Y. Wang, T. Fumitake, T. Kouji, A. Li and Y. Kunio, Appl. Energy, 2017, 185, 146-157.

33 Z. Gong, Z. Wang, Z. Wang, A. Du, P. Fang, Z. Sun and X. Li, Can. J. Chem. Eng., 2018, 96, 1919-1925.

34 J. Liu, X. Jiang, L. Zhou, X. Han and Z. Cui, J. Hazard. Mater., 2009, 161, 1208-1215.

35 D. Choudhury, R. C. Borah, R. L. Goswamee, H. P. Sharmah and P. G. Rao, J. Therm. Anal. Calorim., 2007, 89, 965-970.

36 F. Kleitz, T.-W. Kim and R. Ryoo, Bull. Korean Chem. Soc., 2005, 26(11), 1653-1668.

37 X. Zhou, H. Jia, C. Qu, D. Fan and C. Wang, Environ. Technol., 2017, 38, 361-369.

38 D. Munir, M. F. Irfan and M. R. Usman, Renewable Sustainable Energy Rev., 2018, 90, 490-515.

39 T. Kim, J. Lee and K.-H. Lee, Carbon Lett., 2014, 15, 15-24. 40 M. Bhattacharya and T. Basak, Energy, 2016, 97, 306-338.

41 J. A. Menéndez, A. Arenillas, B. Fidalgo, Y. Fernández, L. Zubizarreta, E. G. Calvo and J. M. Bermúdez, Fuel Process. Technol., 2010, 91, 1-8.

42 İ. Ertuğrul and İ. Alime, Turk. J. Chem., 2007, 31, 523-530.

43 R. Wahi, A. Idris, M. M. Salleh and K. Khalid, Int. J. Eng. Technol., 2006, 3, 132-138.

44 L. Wang, C. Yin, Z. Shan, S. Liu, Y. Du and F.-S. Xiao, Colloids Surf., A, 2009, 340, 126-130.

45 J. Zeaiter, Fuel, 2014, 133, 276-282.

46 B. K. Sharma, B. R. Moser, K. E. Vermillion, K. M. Doll and N. Rajagopalan, Fuel Process. Technol., 2014, 122, 70-90.

47 D. P. Serrano, J. Aguado and J. M. Escola, ACS Catal., 2012, 2(9), 1924-1941.

48 L. P. Chrysikou, V. Dagonikou, A. Dimitriadis and S. Bezergianni, J. Cleaner Prod., 2019, 219, 566-575.

49 P. Gaurh and H. Pramanik, J. Cleaner Prod., 2018, 71, 86-96. 50 A. Ramanathan, H. Zhu, R. Maheswari, P. S. Thapa and B. Subramaniam, Ind. Eng. Chem. Res., 2015, 54, 4236-4242.

51 R. Thahir, A. Altway, S. R. Juliastuti and Susianto, Energy Rep., 2019, 5, 70-77.

52 S. D. A. Sharuddin, F. Abnisa, W. M. A. W. Daud and M. K. Aroua, Energy Convers. Manage., 2016, 115, 308-326.

53 M. Kumar, M. P. Sharma and G. Dwivedi, Int. J. Renew. Energy Res., 2013, 3, 913-921. 